\title{
Effect of progressive relaxation technique in reducing epileptic seizures among adolescents
}

\author{
Amany Sobhy Sorour ${ }^{1}$, Noha Ahmed Mohamed ${ }^{2}$ \\ 1. Faculty of Nursing, Zagazig University, Zagazig, Egypt. 2. Faculty of Nursing, Beni-Suef University, Beni-Suef, Egypt. \\ Correspondence: Noha Ahmed Mohamed. Address: Faculty of Nursing, Beni-Suef University, Beni-Suef, Egypt. Email: \\ dr_nohaahmed@yahoo.com
}

Received: November 28, 2013

Accepted: February 9, 2014

Online Published: April 2, 2014

DOI : $10.5430 /$ jnep.v4n7p8

URL: http://dx.doi.org/10.5430/jnep.v4n7p8

\begin{abstract}
Epilepsy is a serious and a common neurological condition of which the medical, psychological and social implications are far-reaching and there is still a paucity of research in the psychology and social issues in epilepsy. The aim of this study was to examine the effect of progressive relaxation technique in reducing epileptic seizures among adolescents. The study was carried out on a convenience sample of 28 secondary school students attending the school health insurance center Beni-Suef city using a quasi-experimental design with pre-post assessment. Data collection tools included an interview questionnaire for the personal and disease characteristics; stress level was assessed using Cohen's (1994) 10-question tool. After a pretest, the researchers trained the participants in applying a stress management exercise, and asked them to practice it at home and to document the frequency and duration of daily practice using a diary for eight weeks. The post-intervention stress level was assessed using the same tool. The results revealed statistically significant changes in all ten items of the stress scale, with a median post-pre total difference of $-0.3(p<.001)$. The number of seizures decreased from a median of $3 /$ week to one seizure in the last four weeks of follow-up $(p<.001)$. A statistically significant weak negative correlation was found between the frequency of seizures and the number of progressive relaxation techniques practiced. The study findings indicate the effectiveness of a simple technique in improving the life of adolescents having epilepsy. However, the small sample size could not show the correlation between the practice of this relaxation technique and the frequency of the seizures. A randomized controlled clinical trial is recommended to confirm the findings.
\end{abstract}

\section{Key words}

Adolescent, Epilepsy, Progressive relaxation techniques, Seizure reduction

\section{I ntroduction}

Epilepsy is a worldwide problem and a complex neurological disorder that affects nearly fifty million people worldwide and $75 \%$ of the cases begin before adolescence. The incidence and prevalence of epilepsy are higher in developing countries than in developed ones. However, despite the higher incidence of epilepsy in developing countries, the prevalence rates are relatively low, probably due to a high mortality of affected people ${ }^{[1]}$. The direct medical care costs for epilepsy are estimated between $\$ 9.6$ billion and $\$ 12.5$ billion per year in the United States ${ }^{[2]}$.

The etiology of epilepsy has been related to genetic, structural, metabolic or sometimes unknown factors. Among the structural factors, the most common causes in developing countries are infectious and parasitic diseases - especially 
neurocysticercosis - perinatal brain damage, vascular disease, and head trauma; all are preventable ${ }^{[3]}$. The condition is characterized by debilitating seizures contributing to impairments in intellectual and cognitive functioning ${ }^{[4]}$.

In addition to cognitive impairments, many patients with epilepsy experience significant emotional distress ${ }^{[5]}$, and many view their main handicaps as psychological rather than purely physical. On the other hand, stress has been consistently identified as one of the most significant seizure precipitants in patients with epilepsy, with nearly two-thirds of patients reporting it as the single biggest predictor of seizure occurrence ${ }^{[6]}$. Moreover, self-reported high anxiety has been associated with a doubling of the risk of seizure the next day compared to self-reported low anxiety scores. These findings suggest a direct link between epilepsy and perceived emotional distress.

Psychological interventions such as psychotherapy, individual, group or family counseling, progressive relaxation therapy and cognitive behavior therapy have been used to treat the psychopathology associated with epilepsy ${ }^{[7]}$. Such interventions are used in attempts to reduce seizure frequency, improve quality of life (QOL) and avoid adverse effects of drugs among people with epilepsy. The epilepsy specialist nurse (ESN) role is complex, diverse and multifaceted, with nurses working with different patient groups in various settings. ESNs are an expert and essential part of a multiDisciplinary team providing clinical and psychosocial information and support for individuals with epilepsy ${ }^{[8]}$.

Despite a long recognized need in the field of the importance of the psychological and social factors in Epilepsy, there is still a paucity of research in the psychology and social issues of the disease ${ }^{[9]}$. There is little research on stress and epilepsy, and none of its effect on cognitive functions such as memory in patients with temporal lobe epilepsy ${ }^{[10]}$. Trials had contradictory results, although educational interventions epilepsy showed some reduction of anxiety and improvement of medication compliance and social competency, but further well designed trials are still needed ${ }^{[11]}$. Moreover, in a recent systematic review, Ferro et al. ${ }^{[12]}$ concluded that a limited number and modest quality of the studies are available on epilepsy in adolescents, and thus future research should focus on exploring the potential role of self-concept in the development of mental health problems in adolescents with epilepsy.

\section{Aim and hypotheses}

The aim of this study was to examine the effect of progressive relaxation technique in reducing epileptic seizures among adolescents. It was hypothesized that the application of progressive relaxation technique to epileptic adolescents leads to significant reductions in their level of stress and in the frequency of seizures among them.

\section{Subjects and methods}

\subsection{Research design and setting}

A quasi-experimental uncontrolled study design with pre-post assessment was used in this study, which was carried out at the outpatient clinics of the school health insurance.

\subsection{Participants}

The study was carried out on a convenience sample of 28 secondary school students attending the school health insurance center for follow-up of their epilepsy. The sample criteria included an age range 15-18 years, a diagnosis of epilepsy by a neurologist, having stress as a trigger factor, free from other chronic disorders and being under treatment for more than one year in the study setting.

\subsection{Data collection tools}

The researchers designed an interview questionnaire form to collect participant's personal (age, gender) as well as disease characteristics as the type of epilepsy, underlying cause, investigations, treatment, frequency, duration, and intensity of 
epileptic seizures, etc. based on the tool of MetLife Insurance Limited ${ }^{[13]}$. The stress level was assessed using Cohen's ${ }^{[14]}$, 10-question tool about students' feelings and thoughts during the last month. It included questions such as "how often have you been upset," "ability to control the important things in your life," etc. The response was on a 5-point Likert scale ranging from "never $=0$ " to "very often=4." The total score was calculated by adding up the scores of the ten items and dividing the sum by 10 , and thus ranged between " 0 " and " 4 ," with a higher score indicating higher levels of stress. The tool was validated through a rigorous review by a panel of five experts in neurology and community health nursing. The internal consistency of the stress scale was tested using Cronbach's alpha coefficient, which proved to be good (0.69).

\subsection{Pilot study}

The tool was pilot-tested to test the applicability and the clarity of the questionnaire and to estimate the time needed for data collection. Since no modifications were made on the tool, the three students in the pilot were included in the main study sample.

\subsection{Procedures}

After approval of the study protocol by the director of the outpatient clinics of the school health insurance, the researchers started recruiting the sample. Eligible students were met, in the presence of their parents, and were invited to participate after explaining to them the purpose of the study and its procedure. Those who gave their consent to participate were interviewed individually using the questionnaire form, including the stress test which was considered as a pretest. Then, the researchers started to train the student in applying the stress management exercise. This exercise is based on adaptations by Bernstein and Borkovec ${ }^{[15]}$ and Antoni ${ }^{[16]}$ of the procedures originally described by Jacobson ${ }^{[17]}$. The researchers started by providing guided instructions to the student such as slow paced breathing, using a chair with comfortable seat and headrest, wearing loose clothing, and taking off shoes, avoid practicing after big heavy meals, and giving time to relax. When ready to start, the student was trained in tensing the muscle group described, making sure he/she can feel the tension. The muscle was to be kept tense for 5 seconds and then relaxed and kept relaxed for 10 seconds. After ending the procedure, the student was instructed to remain seated for a few minutes, allowing him/herself to become alert. The student was asked to practice the technique several times in the presence of the researcher to ensure that he/she can perform it effectively. Each student was provided with a diary to document the frequency and duration of performing the daily exercise, as well as the frequency and duration of epileptic seizures. The researchers made follow-up phone calls twice per week for eight weeks. At the end of the follow-up period, each student was re-interviewed to assess his/her post-intervention stress level using the same data collection tool.

\subsection{Ethical considerations}

An informed consent was obtained from the parents and assent from each adolescent to participate in the study. The form explains the study aim in a simple and clear manner to be understood by common people. No harmful procedure was performed or used, and no foreseen hazards were anticipated from conducting the study on these patients. Participants were informed about their right to withdraw from the study at any time without giving any reason. Data were considered confidential and not be used outside this study without the patient's approval. The researcher phone number and all possible communicating methods were identified to the participants to return at any time for any explanation.

\subsection{Statistical analysis}

Data entry and statistical analysis were done using SPSS 18.0 statistical software package. Data were presented using descriptive statistics in the form of frequencies and percentages for qualitative variables, and means and standard deviations and medians for quantitative ones. Quantitative continuous data were compared using a paired t-test for pre-post comparisons. The non-parametric Kruskal-Wallis test was used for multiple group comparisons. Pearson correlation analysis was used for assessment of the interrelationships among numeric variables. Statistical significance was considered at $p$-value $<.05$. 


\section{Results}

The study sample revealed a higher ratio of males to females (17/11), and the median age was 17 years (see Table 1). More than two-thirds had temporal lobe epilepsy with a history of loss of consciousness (71.4\%). Head injury was the most commonly reported underlying cause (39.3\%), while in $35.7 \%$ of the cases no cause was identified. Only six (21.4\%) of the students had regular absence from school and/or restricted activities due to their disease.

Table 2 indicates statistically significant changes in all ten items of the stress scale. The total score decreased at a range between -0.1 and -1.3 from a maximum of 4 , with a median post-pre difference of -0.3 . This difference was statistically significant $(p<.001)$.

Table 3 The number of epileptic seizures throughout the follow-up period demonstrated a steady decrease from a median of three fights per week in the first two weeks to a median of one seizure in the last four weeks of follow-up. This decreasing trend was statistically significant.

Table 4 illustrates a statistically significant weak negative correlation between the frequency of epileptic seizures and the number of progressive relaxation techniques practiced during the intervention. Although the stress level at the end of the intervention correlated positively with the total number of seizures, the relation did not reach statistical significance $(p$ $=.06)$.

Table 1. Age and gender and characteristics of epilepsy among patients in the study sample $(n=28)$

\begin{tabular}{|c|c|c|}
\hline & Frequency & Percent \\
\hline \multicolumn{3}{|l|}{ Age (years): } \\
\hline$<18$ & 22 & 78.6 \\
\hline 18 & 6 & 21.4 \\
\hline Range & $15-18$ & \\
\hline Mean \pm SD & $17.1 \pm 1.4$ & \\
\hline Median & 17 & \\
\hline \multicolumn{3}{|l|}{ Gender: } \\
\hline Male & 17 & 60.7 \\
\hline Female & 11 & 39.3 \\
\hline \multicolumn{3}{|l|}{ Type of epilepsy: } \\
\hline Grand mal & 3 & 10.7 \\
\hline Petit mal & 5 & 17.9 \\
\hline Temporal lobe & 20 & 71.4 \\
\hline \multicolumn{3}{|l|}{ Lose consciousness: } \\
\hline No & 8 & 28.6 \\
\hline Yes & 20 & 71.4 \\
\hline \multicolumn{3}{|l|}{ Duration (min): } \\
\hline Range & $10.0-30.0$ & \\
\hline Mean $\pm \mathrm{SD}$ & $20.0 \pm 8.9$ & \\
\hline Median & 17.0 & \\
\hline \multicolumn{3}{|l|}{ Underlying cause: } \\
\hline None & 10 & 35.7 \\
\hline Head injury & 11 & 39.3 \\
\hline Psychic trauma & 5 & 17.9 \\
\hline Hypertension & 2 & 7.1 \\
\hline \multicolumn{3}{|l|}{ Medications: } \\
\hline Depakin & 11 & 39.3 \\
\hline Tegretol & 11 & 39.3 \\
\hline Decal & 2 & 7.1 \\
\hline Topamax & 4 & 14.3 \\
\hline Have regular absence from school/restricted activities & 6 & 21.4 \\
\hline
\end{tabular}


Table 2. Pre-post-intervention changes in the stress scores among patients in the study sample

\begin{tabular}{|c|c|c|c|c|c|}
\hline \multirow{2}{*}{ Post stress scores(PSS) } & \multicolumn{3}{|c|}{ Post-pre score difference } & \multirow{2}{*}{$\begin{array}{l}\text { Paired } \\
t \text {-test }\end{array}$} & \multirow{2}{*}{$p$} \\
\hline & Range & Mean \pm SD & Median & & \\
\hline PS1 & $-3.0-0.0$ & $-1.6 \pm 1.0$ & -2.00 & 9.14 & $<.001 *$ \\
\hline PS2 & $-3.0-0.0$ & $-1.9 \pm 0.8$ & -2.00 & 12.23 & $<.001 *$ \\
\hline PS3 & $-3.0-0.0$ & $-1.8 \pm 1.0$ & -2.00 & 9.58 & $<.001 *$ \\
\hline PS4 & $0.0-4.0$ & $1.6 \pm 1.1$ & 1.00 & 7.50 & $<.001 *$ \\
\hline PS5 & $0.0-4.0$ & $1.6 \pm 1.1$ & 1.50 & 7.70 & $<.001 *$ \\
\hline PS6 & $-3.0-0.0$ & $-1.8 \pm 0.9$ & -2.00 & 10.44 & $<.001 *$ \\
\hline PS7 & $-3.0-4.0$ & $1.4 \pm 2.1$ & 1.00 & 3.29 & $.003 *$ \\
\hline PS8 & $0.0-3.0$ & $1.4 \pm 0.8$ & 1.00 & 9.57 & $<.001 *$ \\
\hline PS9 & $-4.0-0.0$ & $-1.7 \pm 1.1$ & -1.00 & 8.15 & $<.001 *$ \\
\hline PS10 & $-4.0-1.0$ & $-1.6 \pm 1.3$ & -2.00 & 6.45 & $<.001 *$ \\
\hline Total stress & $-1.3-0.1$ & $-0.4 \pm 0.3$ & -0.30 & 6.94 & $<.001 *$ \\
\hline
\end{tabular}

(*) Statistically significant at $p<.05$

Table 3. Changes in the number of epileptic seizures among patients in the study sample throughout follow-up weeks

\begin{tabular}{|c|c|c|c|c|c|}
\hline \multirow{2}{*}{ Weeks } & \multicolumn{3}{|c|}{ No. of seizures/week } & \multirow{2}{*}{ Kruskal Wallis Test } & \multirow{2}{*}{$p$} \\
\hline & Range & Mean \pm SD & Median & & \\
\hline 1 & $0-6$ & $3.1 \pm 1.3$ & 3 & & \\
\hline 2 & $0-7$ & $2.6 \pm 1.4$ & 3 & & \\
\hline 3 & $0-5$ & $2.3 \pm 1.2$ & 2 & & \\
\hline 4 & $0-7$ & $1.9 \pm 1.5$ & 2 & 49.68 & $<.001^{*}$ \\
\hline 5 & $0-5$ & $1.5 \pm 1.6$ & 1 & & \\
\hline 6 & $0-5$ & $1.2 \pm 1.4$ & 1 & & \\
\hline 7 & $0-5$ & $1.3 \pm 1.5$ & 1 & & \\
\hline 8 & $0-3$ & $1.0 \pm 1.1$ & 1 & & \\
\hline
\end{tabular}

$(*)$ Statistically significant at $p<.05$

Table 4. Correlation between the total number of epileptic seizures and number of relaxation techniques (RT) practiced and stress level score

\begin{tabular}{lll}
\hline & Total number of seizures & \\
\cline { 2 - 3 } & Spearman rank correlation & $\boldsymbol{p}$ \\
\hline A number of relaxation techniques (RT) practiced & -0.27 & $<.001^{*}$ \\
Stress level (end of follow-up) & 0.36 & .06 \\
\hline
\end{tabular}

\section{Discussion}

This study was carried out to examine the effect of progressive relaxation technique in reducing epileptic seizures among adolescents. The study findings indicated significant decreases in the level of stress among participants after implementation of the intervention and this was associated with significant reduction in the frequency of seizures among them. The findings lead to acceptance of the set research hypothesis.

The study sample consisted of adolescent students and this age group was purposefully selected given the high incidence of epilepsy in this age ${ }^{[5]}$, in addition to the importance of early proper management to avoid the possible complications of the disease on the mental and psycho-social development of the adolescent. In agreement with this, Wu et al. ${ }^{[18]}$ in a study of Chinese adolescents with epilepsy found significant impairments in memory/concentration, physical functioning and social support compared with those of normal controls. Hence, they recommended more attention to the seizure-related psychological status of adolescents with epilepsy to improve their physical and mental development. 
According to the current study results, the application of the progressive relaxation technique was associated with a significant reduction in the level of stress among the adolescents with epilepsy. The finding is of great importance given the relation between stress as a trigger factor and the occurrence of epileptic seizures ${ }^{[19]}$. Therefore, our intervention was successful in reducing this trigger factor, which is a kind of coping mechanism that can help the adolescent to prevent the seizure by relieving his/her stress. In fact, such mechanisms to improve the coping of adolescents with epilepsy with stress have been recommended to mitigate some of the problems with adaptive functioning ${ }^{[20]}$, which may help reduce the frequency of the fetus. Moreover, in a study in Australia, the most common triggers of seizures were tiredness, stress, and sleep deprivation, and resting and relaxation were among the most commonly reported techniques used to stop it ${ }^{[21]}$.

The ultimate goal of the present study intervention was to reduce the frequency of epileptic seizures among adolescents, and this was achieved as evident from the significant reduction in the number of seizures throughout the follow-up period. The finding is in congruence with previous studies which reported similar successes of strategies adjuvant to pharmacological therapy. For example, Puskarich et al. ${ }^{[7]}$ reported the success of progressive relaxation therapy in seizure reduction and recommended its incorporation in clinical practice. On the same line, McElroy-Cox ${ }^{[22]}$ mentioned that up to $44 \%$ of patients with epilepsy are successfully using some form of complementary alternative medicine treatment including meditation, relaxation techniques, and biofeedback. Additionally, Elsas et al. ${ }^{[23]}$ demonstrated that an epilepsy-specific behavioral approach comprising counseling and relaxation was successful in reducing or even eliminating emotional-triggered seizures. A similar report of the effectiveness of behavioral therapy in epilepsy as an adjunct to pharmacotherapy has been shown by Polak et al. ${ }^{[24]}$ who has also discussed the challenges of research in this area.

The current study has also revealed a significant negative correlation between the frequency of using the progressive relaxation technique and the frequency of seizures during the study period. This adds support to the positive effect of such technique in reducing the number of seizures. However, the lack of significant correlation between stress and the number of seizures might be due to the small sample size and the p-value was just near significance $(p=.06)$. Therefore, it may be stipulated that the practice of progressive relaxation technique led to reduction through the relief of stress. In agreement with this, Dionisio et al. ${ }^{[25]}$ showed that stress increases the frequency of epileptic seizures. Hence, Haut et al. ${ }^{[6]}$ reported the majority of their study sample was willing to try stress reduction techniques for seizure control.

From another perspective, the practice of progressive relaxation technique by students in the study group may have also acted on the reduction of seizures through improving the self-concept and self-esteem among them, a problem that has been frequently mentioned in research addressing adolescents with epilepsy where aggressive behavior and externalizing problems were found to be higher in this group ${ }^{[20]}$, along with compromised self-concept ${ }^{[12]}$. These issues are of particular importance in adolescence since the normal needs and concerns associated with being an adolescent are complicated by the demands of this morbid condition that places additional limits on lifestyle and independence ${ }^{[26]}$. Engaging in relaxation techniques and the feeling that they are cared for, with regular follow-up may have improved these psycho-social problems, with subsequent relief of stress and improvement in the incidence of seizures. In line with this, Engelbertsa et al. ${ }^{[27]}$ reported positive results in an intervention based on comprehensive care better psychological outcome and seizure reduction.

\section{Conclusion and recommendations}

The study findings indicate the merits of a simple technique in improving the life of adolescents having epilepsy through reducing the frequency of their seizures. However, the small sample size could not show the correlation between the level of stress and the frequency of the seizures. The results also need to be cautiously interpreted given the quasi-experimental design. Hence, it is recommended to carry out a randomized controlled clinical trial to confirm the findings. Nonetheless, since the technique is simple, inexpensive, and harmless, it could be applied on adolescents with epilepsy, with long-follow-up period to show its long-term effects. 


\section{References}

[1] Barragan E.P. Epilepsy and Related Psychiatric Conditions Suggested citation: Barragan E. Epilepsy and related psychiatric conditions. In Rey JM (Ed), IACAPAP e-Textbook of Child and Adolescent Mental Health. Geneva: International Association for Child and Adolescent Psychiatry and Allied Professions 2012.

[2] Yoon D., Frick K.D., Carr D.A., \& Austin J.K. Economic impact of epilepsy in the United States. Epilepsia. 2009 ; 50: $2186-2191$. PMid:19508694 http://dx.doi.org/10.1111/j.1528-1167.2009.02159.x

[3] Barragan E. [Daö Neurolgico y Epilepsia: Estrategia yHerramientas Multidisciplinarias de Apoyo] 2nd ed. Mexico DF: Editorial Linae.

[4] Hermann B., \& Seidenberg M. Neuropsychology and temporal lobe epilepsy. CNS Spectrums. 2002; 7(5): $343-348$. PMid:15122106

[5] Reuber M., Andersen B., Elger C., \& Helmstaedter C. Depression and anxiety before and after temporal lobe epilepsy. Seizure. 2004; 13: 129-135. http://dx.doi.org/10.1016/S1059-1311(03)00073-6

[6] Haut S.R., Vouyiouklis M., \& Shinnar S. Stress and epilepsy: A patient perception survey. Epilepsy and Behavior. 2003; 4: 511-514. http://dx.doi.org/10.1016/S1525-5050(03)00182-3

[7] Puskarich C.A., Whitman S., Dell J., Hughes J.R., Rosen A.J., Hermann B.P. Controlled Examination of Effects of Progressive Relaxation Training on Seizure Reduction. Epilepsia. 2005; 33(4): 675-680.

http://dx.doi.org/10.1111/j.1528-1157.1992.tb02346.x

[8] National Institute for Health and Clinical Excellence (NICE). The epilepsies: The diagnosis and management of the epilepsies in adults and children in primary and secondary care. [CG137]. London: NICE; 2012.

[9] Elliott J.O. The biopsychosocial model and quality of life in persons with active epilepsy Dissertation, 2012.

[10] Haut S., Hall C., Masur J., \& Lipton R. Seizure occurrence: Precipitants and prediction. Neurology. 2007; 69: 1905-1910. PMid:17998482 http://dx.doi.org/10.1212/01.wnl.0000278112.48285.84

[11] Ramaratnam S., Baker G.A., \& Goldstein L.H. Psychological treatments for epilepsy (Review) The Cochrane Library The Cochrane Collaboration. Published by JohnWiley \& Sons, Ltd. Issue 3, 2011.

[12] Ferro M.A., Ferro A.L., \& Boyle M.H. A systematic review of self-concept in adolescents with epilepsy. J Pediatr Psychol. 2012; 37(9): 945-58. PMid:22711910 http://dx.doi.org/10.1093/jpepsy/jss076

[13] MetLife Insurance Limited. Duty of Disclosure (Insurance Contracts Act 1984), affiliated of MetLife, Inc. (Incorporated in the USA), 2008.

[14] Cohen S. The PSS Scale is reprinted with permission of the American Sociological Association, A global measure of perceived stress. Journal of Health and Social Behavior. 1994; 24: 386-396.

[15] Bernstein D. A., \& Borkovec T.D. Progressive relaxation training: A manual for the helping professions. Champaign, IL: Research Press, 1973.

[16] Antoni M.H. Stress management intervention for women with breast cancer. Washington, D.C: American Psychological Association, 2003.

[17] Jacobson E. Progressive relaxation: a physiological and clinical investigation of muscular state and their significance. Chicago: University of Chicago Press, 1938.

[18] Wu D.Y., Ding D., Wang Y., \& Hong Z. Quality of life and related factors in Chinese adolescents with active epilepsy. Epilepsy Res. 2010; 90(1-2): 16-20. PMid:20347264 http://dx.doi.org/10.1016/j.eplepsyres.2010.03.001

[19] Frucht M.M., Quigg M., Schwaner C., Fountain N.B. Distribution of seizure precipitants among epilepsy syndromes. Epilepsia. 2000; 41: 1534-1539. PMid:11114210 http://dx.doi.org/10.1111/j.1499-1654.2000.001534.x

[20] Cengel-Kültür S.E., Ulay H.T., Erdağ G. Ways of coping with epilepsy and related factors in adolescence. Turk J Pediatr. 2009; 51(3): 238-47. PMid:19817267

[21] Pinikahana J., Dono J. The lived experience of initial symptoms of and factors triggering epileptic seizures. Epilepsy Behav. 2009; 15(4): 513-20. PMid:19559655 http://dx.doi.org/10.1016/j.yebeh.2009.06.004

[22] McElroy-Cox C. Alternative approaches to epilepsy treatment. Current Neurology and Neuroscience Reports. 2009; 9(4): 313-318. PMid:19515284 http://dx.doi.org/10.1007/s11910-009-0047-0

[23] Elsas S.M., Gregory W.L., White G., Navarro G., Salinsky M.C., Andrews D.J. Aura interruption: the Andrews/Reiter behavioral intervention may reduce seizures and improve quality of life - a pilot trial. Epilepsy Behav. 2011; 22(4): 765-72. PMid:22056814 http://dx.doi.org/10.1016/j.yebeh.2011.09.030

[24] Polak E.L., Privitera M.D., Lipton R.B., Haut S.R. Behavioral intervention as an add-on therapy in epilepsy: designing a clinical trial. Epilepsy Behav. 2012; 25(4): 505-10. PMid:23153715 http://dx.doi.org/10.1016/j.yebeh.2012.09.012 
[25] Dionisio J., Tatum W.O. Triggers and techniques in termination of partial seizures. Epilepsy Behav. 2010; 17: $210-214$. PMid:20060785 http://dx.doi.org/10.1016/j.yebeh.2009.11.027

[26] Collins S. The psychosocial effect of epilepsy on adolescents and young adults. Nurse Stand. 2011; 25(43): 48-56. PMid:21847868 http://dx.doi.org/10.7748/ns2011.06.25.43.48.c8596

[27] Engelbertsa N.H.J., Kleinb M., Kasteleijn-Nolst Trenitéc D.G.A., Heimansd J.J., \& van der Ploegb H.M. The effectiveness of psychological interventions for patients with relatively well-controlled epilepsy. Epilepsy \& Behavior. 2003; 3(5): 420-426. http://dx.doi.org/10.1016/S1525-5050(02)00522-X 